\title{
Building Information Modeling (BIM) Technology Acceptance Analysis Using Technology Acceptance Model (TAM)
}

\author{
Felix Andrian Prihatono and Tri Joko Wahyu Adi \\ Department of Civil Engineering, Institut Teknologi Sepuluh Nopember, Surabaya \\ e-mail: felix.andrian@gmail.com
}

\begin{abstract}
The growth of an industry growth couldn't be separated from technology development. Nowadays, technology development mostly affected by digitalization, which brought us to industry 4.0 era. The same thing also occurs in construction industry, although its development relatively slower than the growth in manufacturing industry. Construction technology, such as Building Information Modeling (BIM), 3D printing, and robotic equipments, has been introduced to construction industry. BIM is defined as digital representation of physical and functional characteristics of a facility, forming a reliable basis for decisions during its life-cycle. However, in the end, technological development in Construction Industry depends on industry players' readiness to accept and implement the most advance technology. This research's focus is on BIM technology acceptance among players in Indonesia Construction Industry. The research will be conducted in Indonesia Construction Industry, data will be collected through questionnaires asked to the industry players, such as, consultants, project owners, and contractors who have already use BIM technology for their projects. The analysis will be conducted using Technology Acceptance Model (TAM). TAM is a model which was developed to enhance our understanding about user acceptance of a technology, thus could enable technology designer and implementator to evaluate the system before it being implemented. The research's result shows that Indonesia Construction Industry is able to accept BIM technology, the conclusion is taken because all the variables used in TAM has higher than 3 on 1 to 5 Likert scale. Path analysis also shows that Attitude Toward Usage variable do not affect Behavioral Intention variable. Direct, Indirect, and Total Effects analysis show that BIM technology acceptance is affected by Perceived of Usefulness. This result could be used as a basis to introduce BIM to new users, that people are more interested in its usefulness rather than ease of use variable.
\end{abstract}

Keywords-AMOS, Construction Industry, Path Analysis, Structural Equation Modeling, Technology Acceptance Model.

\section{INTRODUCTION}

A UTODESK introduced BIM technology in 2002. Since then, BIM technology has developed rapidly with design and construction technology vendors starting to develop their own BIM technology. BIM technology then began to be used in the construction industry, as well as in Indonesia. Knowledge of acceptance and the factors that influence the acceptance of BIM technology will assist in the process of adaptation of the technology in the construction industry in Indonesia. This research will analyze the acceptance of BIM technology, along with the factors that influence it using the Technology Acceptance Model (TAM). TAM is the first model developed by Davis et al. (1989), which is used to analyze the acceptance of technology along with the factors that influence the acceptance of that technology. Analysis in this research will be carried out on Indonesian construction industry players consisting of consultants, contractors, and owners of construction works.

Based on an explanation of the research background, the following research problems can be formulated as follows:

1. Can Building Information Modeling (BIM) technology be accepted in the Indonesian Construction Industry?

2. What are the critical factors for BIM technology to be accepted and implemented in the Indonesian construction industry?

Based on the background and problem formulation of the study, the purpose of the study is

1. Analyzing the acceptance of BIM technology in the Indonesian Construction Industry.

2. Analyzing critical factors that influence the acceptance of BIM technology in the Indonesian construction industry.

\section{METHODS}

BIM's benefit is not only limited to the planning and design stages of a project but also contributes during the project/building life cycle, including cost management, construction management, project management, and operations. BIM's utilization in construction management is intended to address issues regarding project completion according to plan with budget constraints, human resources, schedules, and limited information. Various disciplines involved in a construction project such as Architects, Civil Engineering, Finance, and others are required to collaborate well to achieve project targets precisely in terms of schedule, cost, and quality. BIM in construction projects provides virtual construction that represents actual construction, intending to reduce uncertainty, increasing safety, solving problems, and conducting simulations and analyzing the impact of an event [10].

Currently available are various BIM software developed by various vendors, each of which has its uniqueness and excellence. BIM software is also intended to improve the efficiency and transparency of the management and implementation of construction work. Even in some countries, the use of BIM has become an obligation for 
The $1^{\text {st }}$ International Conference on Business and Engineering Management (IConBEM)

February $1^{\text {st }} 2020$, Institut Teknologi Sepuluh Nopember, Surabaya, Indonesia

Table 1.

Variables used in various TAM research

\begin{tabular}{lll}
\hline \hline \multicolumn{1}{c}{ Accesibility } & \multicolumn{1}{c}{ Anxiety } & \multicolumn{1}{c}{ Attitude } \\
\hline Compatibility & Complexity & Result Demonstability \\
Perceived Enjoyment & End User Support & Experience \\
Facilitating Conditions & Image & Job Relevance \\
Managerial Support & Playfulness & Personal Innovativeness \\
Relative Advantage & Self-Efficacy & Social Influence, Subjective Norms and Social Pressure \\
Social Presence & Trialability & Usability \\
Visibility & Voluntariness & \\
\hline \hline
\end{tabular}

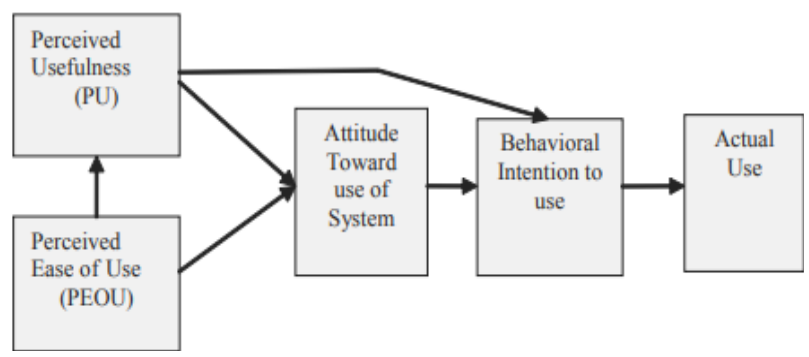

Figure 1. Technology Acceptance Model.

construction work in government projects. Along with the development of information technology, the cost of using BIM software is also getting lower. The BIM function itself is more than just Computer-Aided Design (CAD). If used correctly per its functions, BIM can help in cost efficiency, find and correct mistakes before they occur in actual implementation, and can also speed up project completion.

\section{A. Building Information Modeling (BIM) Benefits}

Building Information Modeling (BIM) usage is increasing and it is also becoming a standard in planning and implementing construction. BIM is growing because it provides more benefits for its users; in this case, the construction industry players. The most significant benefit that BIM can provide is its ability to facilitate collaboration and communication between designers, contractors, and project owners.

Various studies on the benefits of using BIM technology have been carried out before. Some of the benefits of using BIM technology can be explained as follows:

1. Improving project quality, BIM Implementation improves project quality by facilitating easy access to construction materials and the process of construction implementation [15].

2. A better understanding of design, 3D applications make it easier for project teams to visualize and understand designs by utilizing several essential functions such as "rendering" and "walkthrough" [6].

3. Providing project life cycle data, information provided by BIM can be utilized for the entire project life cycle [4].

4. Clarifying the scope, BIM is the right tool to check for discrepancies and reduce differences in design drawings [1].

5. Speeding up the design process, BIM makes it easy for all project stakeholders to understand and approve designs faster [6].

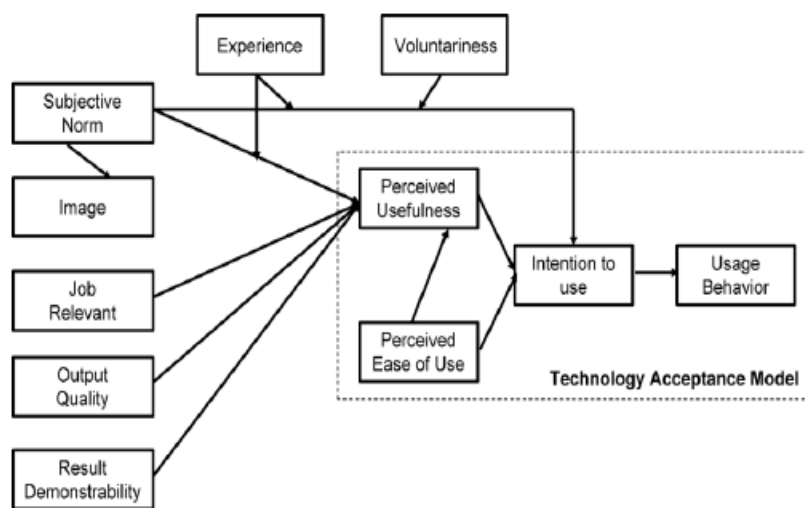

Figure 2. Model TAM2 [14]

6. Reducing construction costs, the Model built with BIM allows it to be used as material for field planning, which can reduce costs and work time [15].

7. Better cost estimation and control, BIM can produce more accurate material requirements and cost calculations compared to manual calculations [7].

8. Improved project planning and supervision, BIM can present a complete project picture and show the stages of the project before project implementation in the field [1].

9. More efficient communication, BIM allows easier and more efficient communication and knowledge sharing in the project team [4].

10. Reducing project duration, the use of BIM allows project completion on time even faster than planned [15].

11. Improve safety performance, BIM can increase the level of job security with simulation features that enable implementers to improve work safety factors in the field [2].

12. Improve the organization's image, the policy of using BIM in an organization or company can improve an organization's image and provide a competitive advantage [15].

\section{B. Technology Acceptance Model (TAM)}

Technology Acceptance Model (TAM) is a model developed by Davis et al. (1989) to measure the acceptance of the technology. Davis et al. (1989) developed TAM based on Theory of Reasoned Action (TRA). TAM uses two main variables, namely Perceived of Usefulness (PU) and Perceived Ease of Use (PEOU) - Usability and Ease of Use as determinants for user acceptance (User Acceptance). The key element used in TAM is behavioral intent that leads to 
The $1^{\text {st }}$ International Conference on Business and Engineering Management (IConBEM)

February $1^{\text {st }}$ 2020, Institut Teknologi Sepuluh Nopember, Surabaya, Indonesia

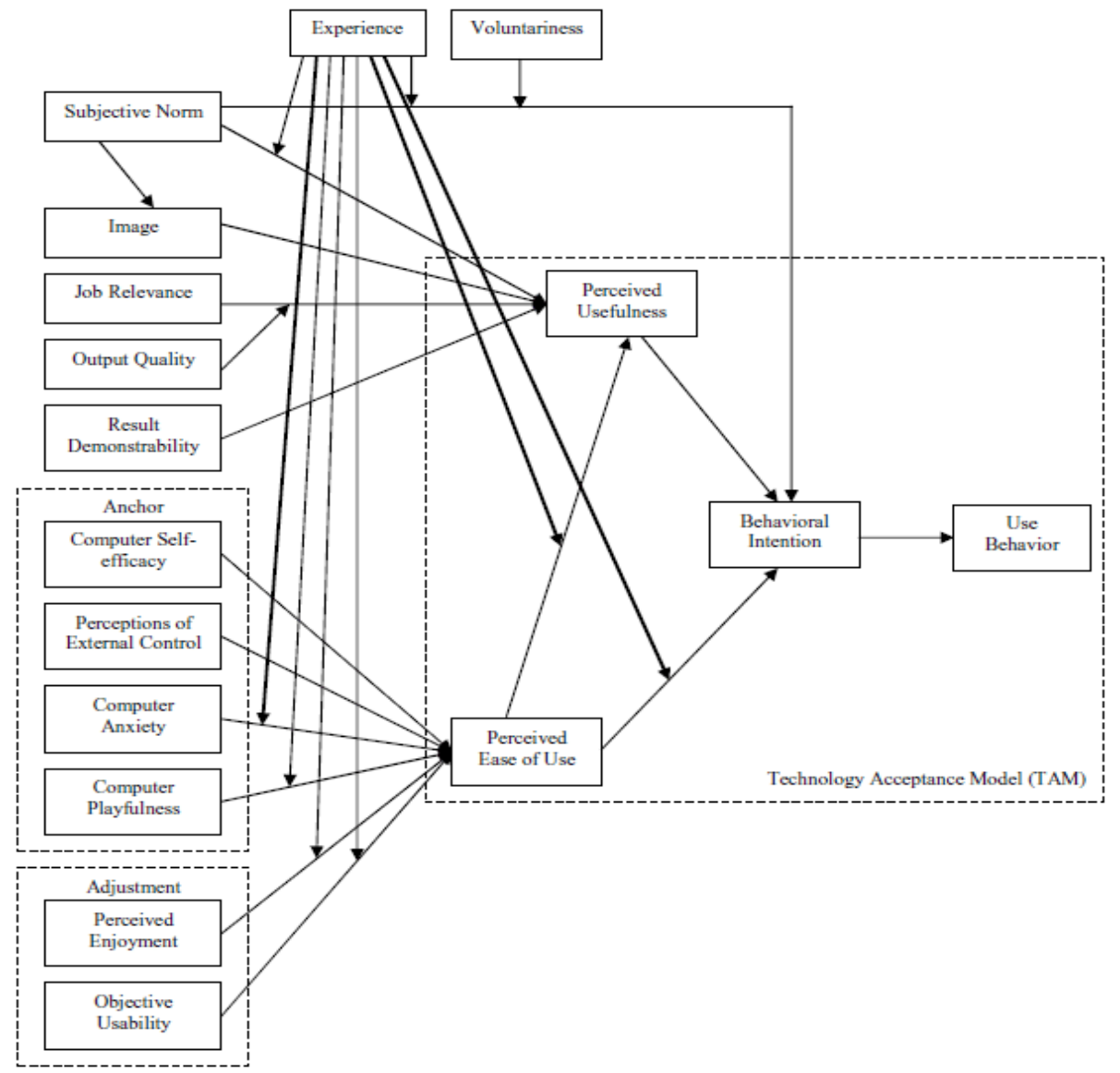

Figure 3. Model TAM3 [13].

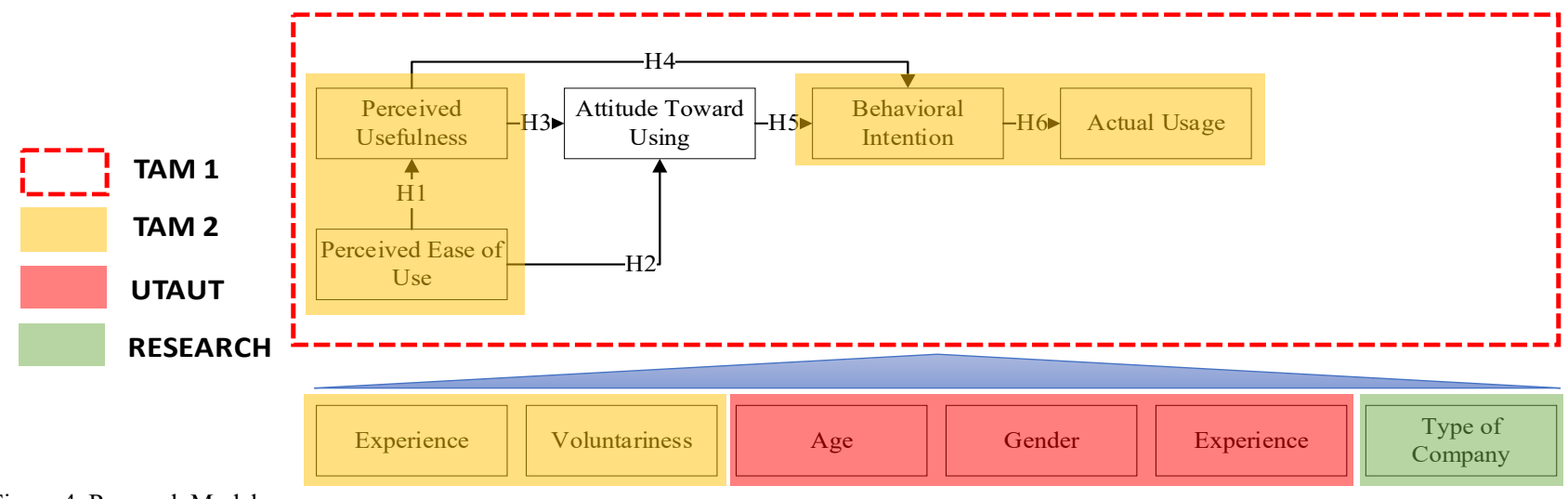

Figure 4. Research Model

the desired behavior, namely the use of the system being tested. TAM evolved from TRA with the aim "to provide an explanation of the determinants of computer acceptance in general, able to explain the behavior of users (users) of various computer technologies and user populations, which are simultaneously parsimonious and can be justified in theory. TAM itself assumes that the actual use of technology is determined by the Behavioral Intent (BI).

The TAM model shown in Figure 1 explains that PU has a direct effect on Attitude Toward Use of System (ATU) and Behavioral Intention to Use (BI), while PEOU has a direct effect on ATU. Although a system is considered beneficial, the system has a tendency to be used if it is also considered to have ease of use (PEOU), where the value of the system's utility $(\mathrm{PU})$ is considered to exceed (outweigh) the effort required to use the system (PEOU). BI will eventually lead to the actual use of the system.

Various studies have been conducted using TAM, where each study uses a variety of external variables in the use of TAM. The variables used in various studies that have been conducted, as shown in Table 1 [8].

The next development of Technology Acceptance Model (TAM) is TAM2 and TAM3 models, wherein the TAM2 the main variables are narrowed to only four variables but also added with moderating variables: Subjective Norms, Image, Job Relevance, Output Quality, and Result Demonstrability as shown in Figure 2.

Whereas the TAM3 model, as shown in Figure 3, introduces anchor and adjustment variables, each of which consists of variables: Computer self-efficacy, perception of 
The $1^{\text {st }}$ International Conference on Business and Engineering Management (IConBEM)

February $1^{\text {st }} 2020$, Institut Teknologi Sepuluh Nopember, Surabaya, Indonesia

Table 2.

Construct Variables Used in The Research.

\begin{tabular}{lll}
\hline \hline No & \multicolumn{1}{c}{ Construct Variables } & \multicolumn{1}{c}{ Definition } \\
\hline 1 & Perceived of Usefulness (PU) & Degree of someone's belief that using a system/technology can improve the performance of his work. \\
2 & Perceived Ease of Use (PEOU) & Degree of someone's belief that the use of a system/technology will be easy (free of effort). \\
3 & Attitude Toward Using (ATU) & Respondent's evaluation of his desire to use the system/technology. \\
4 & Behavioral Intention (BI) & Likelihood of respondents to use BIM technology to complete their work [16] \\
.5 & Actual Usage (AU) & Frequency of use and duration of system/technology usage. \\
\hline
\end{tabular}

Table 3.

Responses for PEOU Variables.

\begin{tabular}{ccc}
\hline Indicators & Mean & Standard Deviation \\
\hline Perceived Ease of Use 1 & 3.410 & 0.924 \\
Perceived Ease of Use 2 & 3.446 & 0.940 \\
Perceived Ease of Use 3 & 3.446 & 0.859 \\
\hline \hline
\end{tabular}

Table 4

Responses for PU Variables.

\begin{tabular}{ccc}
\hline \hline Indicators & Mean & Standard Deviation \\
\hline Perceived of Usefulness 1 & 4.000 & 0.796 \\
Perceived of Usefulness 2 & 4.084 & 0.719 \\
Perceived of Usefulness 3 & 4.012 & 0.789 \\
\hline \hline
\end{tabular}

external control, computer anxiety, computer playfulness, perceived enjoyment, and objective usability. The TAM3 model retains the variables that previously used in the TAM2 model.

\section{Structural Equation Modeling (SEM)}

Structural Equation Modeling (SEM) is a statistical tool used to solve multilevel models simultaneously, which cannot be solved by linear regression equations. SEM can also be considered as a combination of regression analysis and factor analysis. SEM can be used to solve the equation model with more than one dependent variable and also the reciprocal influence (recursive). SEM is based on covariance analysis, so it gives a more accurate covariance matrix than linear regression analysis. Statistical programs that can be used to complete SEM are Analysis Moment of Structure (AMOS) or LISREL.

Technology Acceptance Model is a theory that explains the acceptance of information technology. Davis (1989) states that TAM evolved from Theory of Reasoned Action (TRA) with the aim "to provide an explanation of the determinants of computer reception in general, able to explain the behavior of users of various computer technologies and user populations, which simultaneously parsimonious and can be justified in theory. "This study uses Building Information Modeling (BIM) technology as an object of research, where BIM was initially been a collaborative concept that began to emerge since the 1970s and has now been developed and implemented by industry players. The application of BIM as a technology is marked by Autodesk, which began introducing BIM technology in 2002 up till now many BIM technologies are being developed by various construction industry technology vendors.

This research will use the Structural Equation Model (SEM) to analyze the TAM model with BIM Technology as
Table 5.

Responses for ATU Variables.

\begin{tabular}{lcc}
\hline \hline Indicators & Mean & Standard Deviation \\
\hline Attitude Toward Using 1 & 3.759 & 0.878 \\
Attitude Toward Using 2 & 3.675 & 0.899 \\
Attitude Toward Using 3 & 3.373 & 0.933 \\
\hline \hline
\end{tabular}

Table 6.

Responses for AU Variables.

\begin{tabular}{ccc}
\hline \hline Indicators & Mean & Standard Deviation \\
\hline Actual Usage 1 & 3.831 & 0.985 \\
Actual Usage 2 & 4.096 & 0.864 \\
Actual Usage 3 & 4.048 & 0.840 \\
\hline \hline
\end{tabular}

the object of research. Based on its purpose, SEM is a tool that can be used to test a theory or confirm a theory, which in this case, is TAM. SEM is used to analyze the relationship between latent variables using data from indicator variables/measuring variables. This study also aims to confirm TAM model and its suitability with BIM as the object of research.

\section{Research Model}

The research model is based on TAM1 and TAM2 models which can be explained in Figure 4.

Based on the model forming as in Figure 4 the next step is to determine the measuring variable based on the construct variable. This research will use 5 (five) TAM extract variables. The construct variables and indicators used can be explained in Table 2 .

\section{RESULTS AND DISCUSSION}

\section{A. Construct Variables Responses}

Table 3 shows the descriptive statistics of the questionnaires processed for the Perceived Ease of Use (PEOU) variables. It appears that all indicators have an average value in the range of 3 (three) from a range of 1 to 5 on the Likert scale.

Table 4 shows the descriptive statistics of the questionnaires processed for the Perceived of Usefulness (PU) variables. It appears that all indicators have an average value in the range of 4 (four) from a range of 1 to 5 on the Likert scale.

Table 5 shows the descriptive statistics of the questionnaires processed for the Attitude Toward Usage (ATU) variables. It appears that all indicators have an average value in the range of 3 (three) from a range of 1 to 5 on the Likert scale. 
Table 7.

Responses for BI Variables.

\begin{tabular}{ccc}
\hline \hline Indicators & Mean & Standard Deviation \\
\hline Behavioral Intention 1 & 3.988 & 0.819 \\
Behavioral Intention 2 & 3.952 & 0.810 \\
Behavioral Intention 3 & 4.157 & 0.740 \\
\hline
\end{tabular}

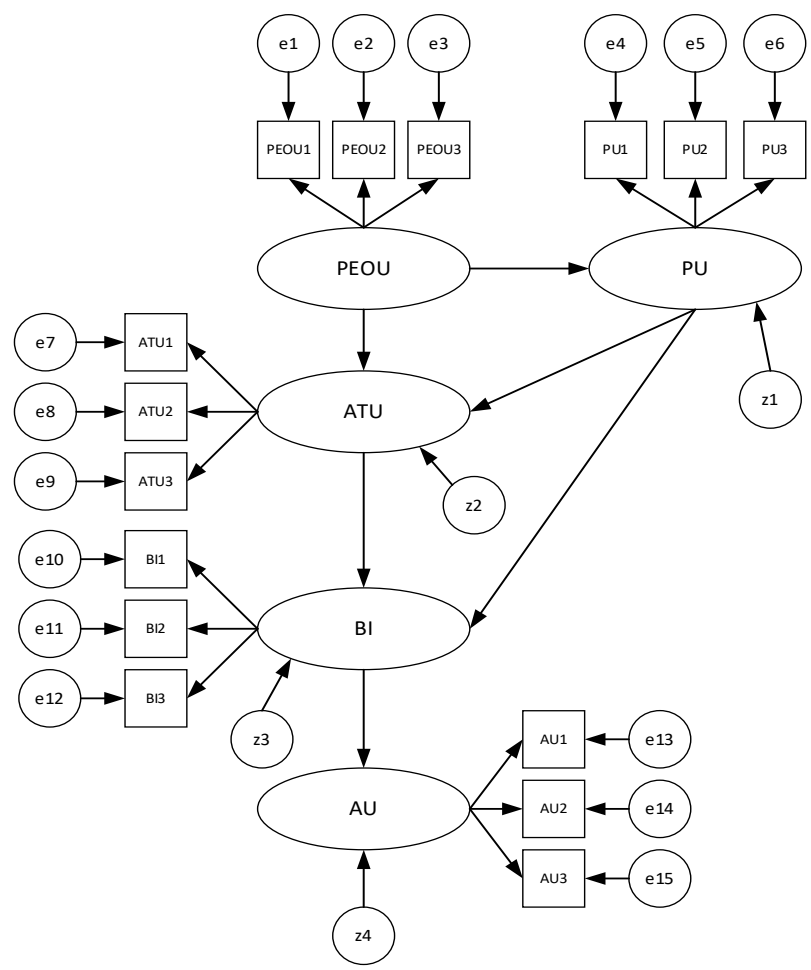

Figure 5. Initial TAM for BIM.

Table 6 shows the descriptive statistics of the questionnaires processed for the Actual Usage (AU) variables. It appears that all indicators have an average value in the range of 4 (four) from a range of 1 to 5 on the Likert scale.

Table 7 shows the descriptive statistics of the questionnaires processed for the Behavioral Intention (BI) variables. It appears that all indicators have an average value in the range of 4 (four) from a range of 1 to 5 on the Likert scale.

\section{B. Initial Model}

Initial Structural Equation Model (SEM) model created using AMOS software by following Technology Acceptance Model (TAM) model can be shown in Figure 5.

\section{Model Modification}

Model modification is required to create a model that fit with the technology being studied, the modification is conducted with model fit analysis. Our model has to be modified through three stages of modification, where the modified model can be shown in Figure 6.

\section{Hypothesis Testing}

Hypothesis testing is carried out to analyze the significance of the regression weight. This analysis is carried out to see the total impact, indirect impact, and direct impact between
Table 8 .

$\mathrm{CR}$ and $\mathrm{P}$ Value for Variables Relation in TAM for BIM.

\begin{tabular}{lcc}
\hline \multicolumn{1}{c}{ Variables Relation } & CR & P \\
\hline $\mathrm{PU} \leftarrow \mathrm{PEOU}$ & 3,227 & 0,001 \\
$\mathrm{ATU} \leftarrow \mathrm{PU}$ & 2,984 & 0,003 \\
$\mathrm{ATU} \leftarrow \mathrm{PEOU}$ & 2,360 & 0,018 \\
$\mathrm{BI} \leftarrow \mathrm{ATU}$ & 1,792 & 0,073 \\
$\mathrm{BI} \leftarrow \mathrm{PU}$ & 2,332 & 0,02 \\
$\mathrm{AU} \leftarrow \mathrm{BI}$ & 4,910 & 0,00 \\
\hline \hline
\end{tabular}

Table 9.

Direct, Indirect, dan Total Effect Analysis.

\begin{tabular}{cccccc}
\hline \hline & PEOU & PU & ATU & BI & AU \\
\hline PU & 0,627 & 0,000 & 0,000 & 0,000 & 0,000 \\
ATU & 0,709 & 0,508 & 0,000 & 0,000 & 0,000 \\
BI & 0,556 & 0,674 & 0,341 & 0,000 & 0,000 \\
AU & 0,553 & 0,670 & 0,339 & 0,994 & 0,000 \\
AU3 & 0,422 & 0,512 & 0,259 & 0,760 & 0,764 \\
AU2 & 0,415 & 0,503 & 0,255 & 0,747 & 0,751 \\
AU1 & 0,340 & 0,412 & 0,208 & 0,611 & 0,615 \\
PEOU3 & 0,933 & 0,000 & 0,000 & 0,000 & 0,000 \\
PEOU2 & 0,520 & 0,000 & 0,000 & 0,000 & 0,000 \\
PEOU1 & 0,460 & 0,000 & 0,000 & 0,000 & 0,000 \\
BI3 & 0,386 & 0,468 & 0,237 & 0,694 & 0,000 \\
BI2 & 0,279 & 0,338 & 0,171 & 0,502 & 0,000 \\
BI1 & 0,510 & 0,619 & 0,313 & 0,918 & 0,000 \\
ATU3 & 0,399 & 0,286 & 0,563 & 0,000 & 0,000 \\
ATU2 & 0,626 & 0,449 & 0,883 & 0,000 & 0,000 \\
ATU1 & 0,481 & 0,345 & 0,678 & 0,000 & 0,000 \\
PU2 & 0,496 & 0,790 & 0,000 & 0,000 & 0,000 \\
PU1 & 0,492 & 0,785 & 0,000 & 0,000 & 0,000 \\
\hline \hline
\end{tabular}

variables in accordance with Technology Acceptance Model (TAM) model. The basis for decision making is based on Critical Ratio (CR) and Probability (P) values. If the $\mathrm{CR}$ value is higher than 1.96, and P-value is less than 0.05, then there is a significant influence on the relationship of the variables tested.

Based on Table 8, it can be seen that the CR value for the relationship between ATU $\rightarrow$ BI is less than 1.96 and the probability is higher than 0,05 . Whereas for the relationship of other variables namely: PEOU $\rightarrow$ PU, PU $\rightarrow$ ATU, PU $\rightarrow$ $\mathrm{BI}$, and $\mathrm{BI} \rightarrow \mathrm{AU}$ showed a positive and significant relationship shown by $C R$ values $>1.96$ and $P$ values lower than 0.05 . Those results means that there is no positive relationship found for ATU $\rightarrow \mathrm{BI}$, thus it will be deleted in the final model.

\section{E. Direct, Indirect, and Total Effect Analysis}

One of AMOS outputs is the Standardized Direct, Indirect Effects, and Total Effects. The Standardized Direct Effects table shows the direct relationship between variables that are connected in a single direction arrow. The Standardized Indirect Effects table shows the indirect effect between construct variables that are not directly connected but are on the same path, while The Standardized Direct Effects table shows the direct effect value between construct variables that are directly connected. 


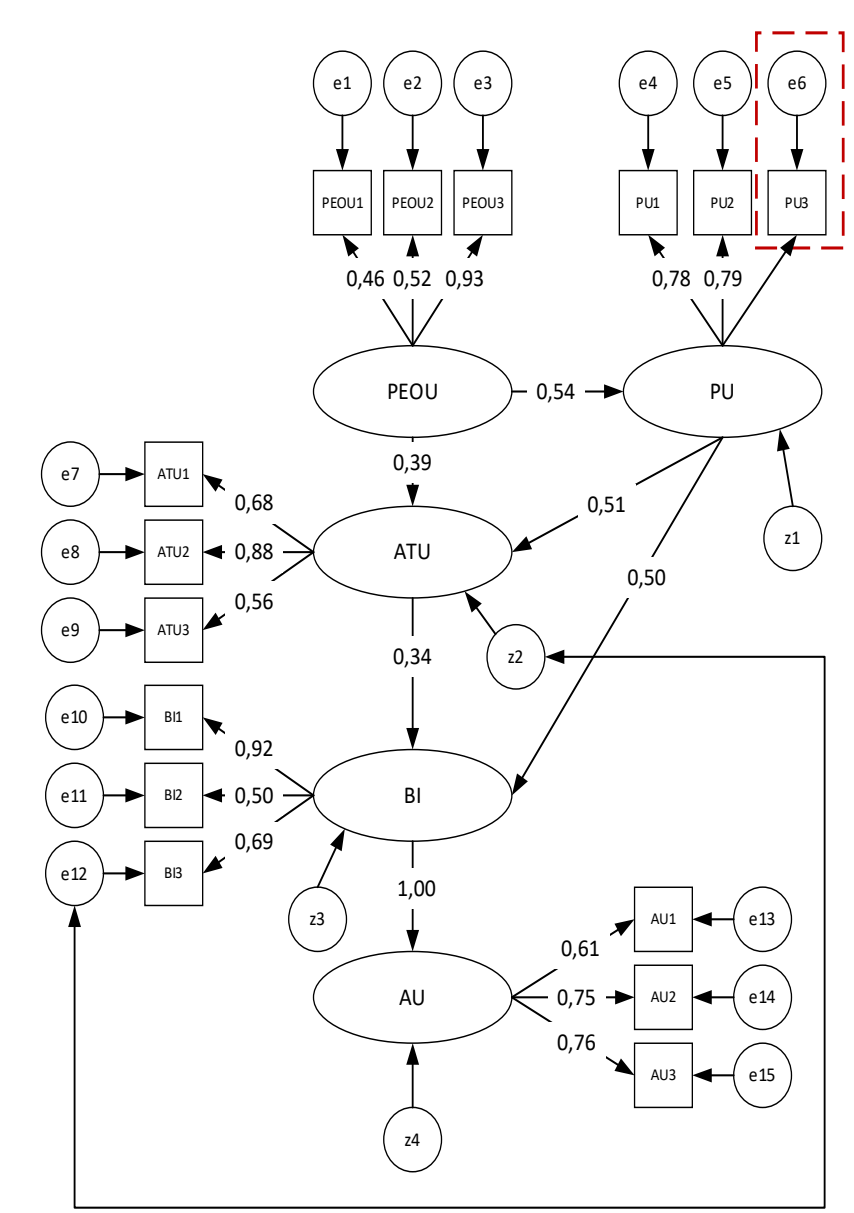

Figure 6. Modified Model

Table 9 shows the total influence value between variables, where it is shown that the highest value of influence on the Actual Usage (AU) variable or actual use is the Behavioral Intention (BI) variable and the Perceived of Usefulness (PU) variable.

\section{CONCLUSSIONS}

Based on the results of data processing and analysis that has been done, can be concluded, the following conclusions can be drawn:

1. The level of acceptance of BIM technology is quite good as indicated by the average Likert scale response of the indicator variables Perceived of Usefulness (PU), Attitude Toward Usage (ATU), Behavioral Intention (BI), and Actual Usage (AU). Where all those indicator variables measured show values of more than 3 (three) from a scale of 1 (one) to 5 (five). Analysis respondent's profile in terms of gender, work experience, age, and category of the company where they worked with indicator variables showed no linkages or significant relationships, so it can be concluded that the respondents' profile did not affect respondents' responses to the indicator variables.

2. The final model of the acceptance of Building Information Modeling (BIM) using the Technology Acceptance Model (TAM) changes from its initial model. The results of the path analysis using the

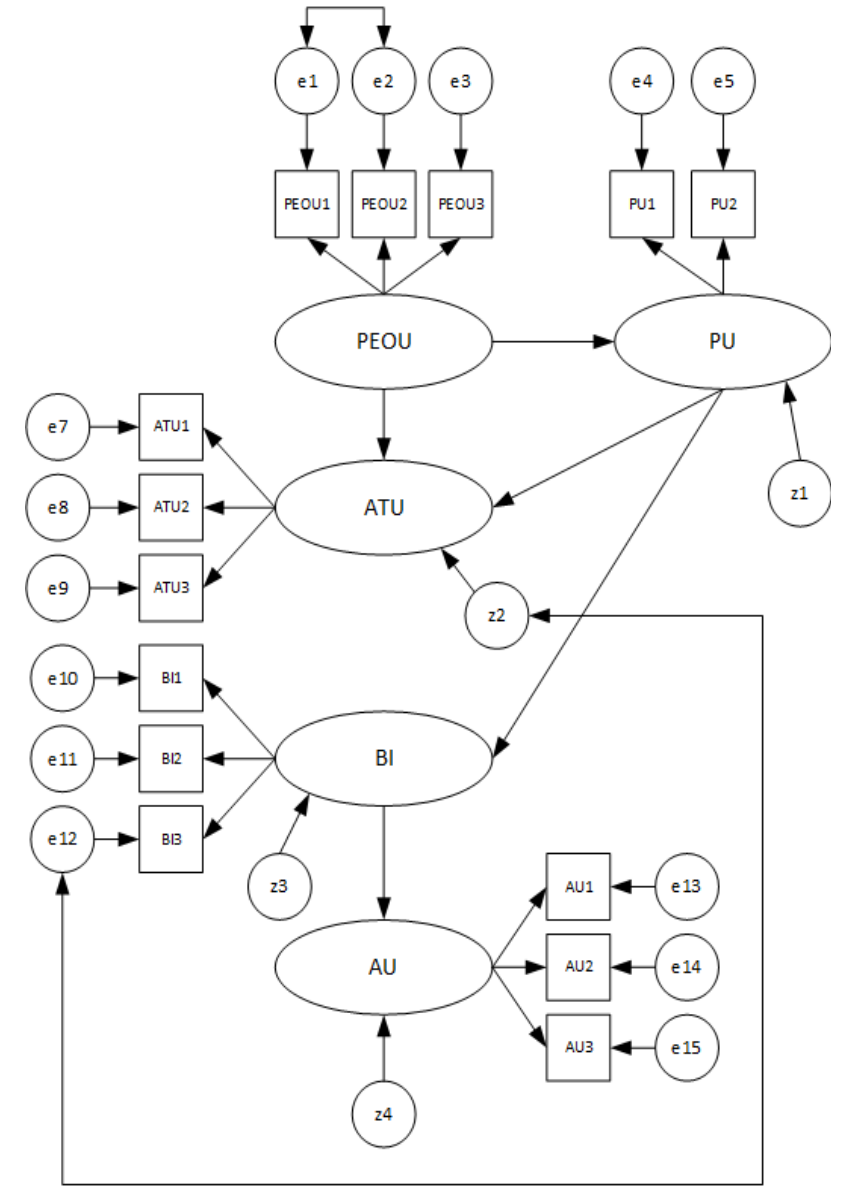

Figure 7. Final Model]

Structural Equation Model (SEM) show that the Attitude Toward Usage (ATU) variable has no influence or positive relationship on other indicator variables in the TAM model for BIM technology acceptance. Analysis of indirect effects (Indirect Effect) shows that the variable Perceived of Usefulness (PU) or the usefulness of BIM has the most significant influence on the variable Actual Usage (AU) or actual use. The analysis of Total Effects also shows that the most significant influence on the Actual Usage variable is the Behavioral Intention and Perceived of Usefulness variables.

3. Indirect Effect analysis results show that the variable that has the most significant indirect effect on the actual use of BIM (AU) technology. The pattern was also shown in the Total Effect analysis, which showed that the variable perception of the usefulness of BIM (PU) technology had the most significant influence on the variable of the actual use of BIM (AU) technology. While the perceived ease of use of BIM technology (PEOU) variables has the highest indirect effect on the intention to use BIM (BI) technology based on the Indirect Effect results. The ease of use of BIM technology affects the behavior of using BIM technology. These results are likely influenced by the factors of respondents who are mostly aged under 30 years $(56.63 \%)$ where individuals in that age range are already quite familiar and adept at using information technology that is the basis of BIM technology. 
The $1^{\text {st }}$ International Conference on Business and Engineering Management (IConBEM)

February $1^{\text {st }} 2020$, Institut Teknologi Sepuluh Nopember, Surabaya, Indonesia

4. The results also show that in the application of BIM technology, it is necessary to pay more attention to the usefulness of BIM implementation, where the factors based on the model will affect the individual's intention to use BIM technology.

\section{REFERENCES}

[1] Ajibade, A., \& Sudha, V. (2014). Status of BIM Adoption and the BIM Experience of Cost Consultants in Australia. Journal of Professional Issues in Engineering Education and Practice, 140(3), 4013021. https://doi.org/10.1061/(ASCE)EI.19435541.0000193

[2] Akinade, O. O., Oyedele, L. O., Bilal, M., Ajayi, S. O., Owolabi, H. A., Alaka, H. A., \& Bello, S. A. (2015). Waste minimisation through deconstruction: A BIM based Deconstructability Assessment Score (BIM-DAS). Resources, Conservation and Recycling, 105 $167-176$. https://doi.org/https://doi.org/10.1016/j.resconrec.2015.10.018

[4] Azhar, S. (2011). Building Information Modeling (BIM): Trends, Benefits, Risks, and Challenges for the AEC Industry. Leadership and Management in Engineering, 11, 241-252. https://doi.org/10.1061/(ASCE)LM.1943-5630.0000127

[5] Indonesia, P. B. D. P. N. R. (2008). Kamus Besar Bahasa Indonesia.

[6] Ku, K., \& Taiebat, M. (2011). BIM Experiences and Expectations: The Constructors' Perspective. International Journal of Construction Education and Research, 7(3), 175-197. https://doi.org/10.1080/15578771.2010.544155
[7] Lee, G., Park, H. K., \& Won, J. (2012). D3 City project Economic impact of BIM-assisted design validation. Automation in Construction, 22, 577-586. https://doi.org/https://doi.org/10.1016/j.autcon.2011.12.003

[8] Lee, Y., Kozar, K. A., \& Larsen, K. (2003). The Technology Acceptance Model: Past, Present, and Future. Technology, 12.

[9] Park, Y., Son, H., \& Kim, C. (2011). Investigating the determinants of construction professionals' acceptance of webbased training: An extension of the technology acceptance model. Automation in Construction.

[10] Smith, D. (2007). An Introduction to Building Information Modeling. Journal of Building Information Modeling, 12-14.

[11] Son, H., Park, Y., Kim, C., \& Chou, J.-S. (2012). Toward an understanding of construction professionals' acceptance of mobile computing devices in South Korea: An extension of the technology acceptance model. Automation in Construction.

[12] US National BIM Standard. (2018). What is a BIM. Retrieved September 23, 2018, from https://www.nationalbimstandard.org/faqs\#faq1

[13] Venkatesh, V., \& Bala, H. (2008). Technology Acceptance Model 3 and a Research Agenda on Interventions. Decision Sciences, 39 (2), 273-315. https://doi.org/10.1111/j.1540-5915.2008.00192.x

[14] Venkatesh, V., \& Davis, F. D. (2000). A Theoretical Extension of the Technology Acceptance Model: Four Longitudinal Field Studies. Management Science, 46(2), 186-204. Retrieved from http://www.jstor.org/stable/2634758

[15] Wong, A., Wong, F., \& Nadeem, A. (2010). Attributes of Building Information Modelling Implementations in Various Countries. Architectural Engineering and Design Management, 6, 288-302. https://doi.org/10.3763/aedm.2010.IDDS6

[16] Wu, J.-H., \& Wang, S.-C. (2005). What drives mobile commerce? An empirical evaluation of the revised technology acceptance model. Information \& Management, 42, 719-729. 